\title{
HTLV-I p30 inhibits multiple $S$ phase entry checkpoints, decreases cyclin E-CDK2 interactions and delays cell cycle progression
}

\author{
Hicham H Baydoun, Joanna Pancewicz, XueTao Bai, Christophe Nicot ${ }^{*}$
}

\begin{abstract}
Background: Human T-cell leukemia virus type I (HTLV-I) has efficiently adapted to its host and establishes a persistent infection characterized by low levels of viral gene expression and slow proliferation of HTLV-I infected cells over decades. We have previously found that HTLV-I p30 is a negative regulator of virus expression.

Results: In this study we show that p30 targets multiple cell cycle checkpoints resulting in a delayed entry into $S$ phase. We found that p30 binds to cyclin E and CDK2 and prevents the formation of active cyclin E-CDK2 complexes. In turn, this decreases the phosphorylation levels of Rb and prevents the release of E2F and its transcriptional activation of genes required for G1/S transition. Our studies also show that HTLV-II p28 does not bind cyclin $E$ and does not affect cell cycle progression.
\end{abstract}

Conclusions: In contrast to HTLV-I, the HTLV-II-related retrovirus is not oncogenic in humans. Here we report that the HTLV-I p30 delays cell cycle progression while its homologue, HTLV-II p28, does not, providing evidence for important differences between these two related retrovirus proteins.

\section{Background}

Cell cycle progression from G1 to $\mathrm{S}$ phase is regulated by the sequential activation of two kinase-complexes, CDK4/6-cyclin D and Cyclin E-CDK2 [1], to ease the inhibition of E2F-mediated transcription. In G1-phase, hypo-phosphorylated $\mathrm{Rb}$ binds to and sequesters the E2F-DP1 transcription factors in a repressive complex containing HDAC, thereby inhibiting the activation of key downstream transcription events [2]. Following phosphorylation of Rb by Cyclin D-CDK4/6 and subsequently by Cyclin E-CDK2, E2F is released from the repressor complex Rb-E2F allowing activation of key genes required for S-phase entry [3].

Unlike the cyclin D-dependent kinases, the activity of cyclin E-Cdk2 is intermittent and reaches a maximum at the G1- to S-phase transition [4-6]. Cyclin E expression and activity is at least in part mitogen-dependent, and its downstream targets include a subset of the G1 inhibitors that are also targeted by the D-type cyclins, $\mathrm{Rb}$ and $\mathrm{p} 27 \mathrm{Kip} 1$. However, the mechanisms by which

\footnotetext{
* Correspondence: cnicot@kumc.edu

University of Kansas Medical Center. Department of Pathology and Laboratory Medicine, Kansas City, 66160 KS USA
}

cyclin $\mathrm{E}$ inactivates these inhibitors differ from those used by cyclin D-dependent kinases, suggesting that their actions may be complementary $[7,8]$. Cyclin $\mathrm{E}$-Cdk2 phosphorylates $\mathrm{Rb}$ on different sites from the cyclin D-dependent kinases, and may differentially affect interactions of $\mathrm{Rb}$ with E2Fs, histone deacetylases, and other chromatin-remodeling factors [9]. The functions of cyclin E-Cdk2 are not strictly limited to G1. Cyclin E-Cdk2 phosphorylates a second set of substrates that are involved in cell duplication; these events affect histone gene expression, centrosome duplication, replication origin licensing, and, possibly, origin firing [10]. Cyclin E is one of the E2F-responsive genes. Once the E2F transcriptional program is initiated and sufficient levels of cyclin E-dependent Cdk2 activity is attained, cells no longer rely on the cyclin D-dependent kinases nor on persistent mitogenic signals and are committed to complete the cell cycle [11].

Human T-cell leukemia virus type I (HTLV-I) was originally isolated from a patient with cutaneous $\mathrm{T}$-cell lymphoma [12]. HTLV-I is the causative agent of adult T-cell leukemia (ATL) [13] and tropical spastic paraparesis/HTLV-associated myelopathy (TSP/HAM) $[14,15]$. 
HTLV-I associated malignancies are characterized by an excessive proliferation of HTLV-I infected T cells [16]. Numerous studies have reported the ability of Tax to target cell cycle checkpoints [17-23]. However, recent studies also suggest that infection with HTLV-I or Tax expression itself may not be sufficient for a sustained active cellular proliferation and that accumulation of genetic defects may be required to bypass cell cycle checkpoints [24-26]. This would in fact explain the ability of HTLV-I transformed cells to proliferate in vivo in the absence of most viral gene expression. Additional studies also showed that several virus-encoded genes, p13, p30, p12 and HBZ, adversely affect cell cycle progression [27-34].

We previously demonstrated that p30 is a posttranscriptional repressor of HTLV-I replication [35]. Additional observations suggested that p30 is a multifunctional protein that selectively regulates cellular and viral gene expression and delays infected cells in their progression to the G2 phase of the cell cycle [28,29,36-40]. In the present study, we show that HTLV-1 p30 delays the cell cycle before the entry into S phase. We also show that the effect of p30 is due to its interaction with the cyclin E key-trigger of the G1/S transition, which in turn reduces the function of the Cyclin E-CDK2 complex and all the downstream events.

\section{Methods}

\section{Plasmids and lentiviral particles}

Lentiviral particles expressing p30-myc or GFP were prepared by transfection of 293FT cells with HR-CMVp30myc or GFP with pDLN and VSV-G, respectively, as previously reported [35]. The genes encoding for HTLV-I p30 and its homologue, HTLV-II p28, proteins were amplified by PCR and cloned in frame with an HA tag of pMH vectors into the HindIII and EcoRI sites. The same sites were used to clone both genes in frame with GFP in pEGFPC1 (clonetech). Cyclin E-myc and CDK2-HA expression vectors were a gift from James $M$. Roberts [41].

\section{Cell Culture and transfection}

Hela cells and 293FT were obtained from the ATCC (American Type Culture Collection). They were maintained in Dubelcco modified Eagle medium, DMEM, complemented with $10 \%$ of fetal bovine serum (Gibco) and $1 \%$ penicillin-streptomycin. Jurkat $\mathrm{T}$ cells were cultured in RPMI complemented with $10 \%$ of fetal bovine serum (Gibco) and 1\% penicillin-streptomycin. Cells were maintained at $37^{\circ} \mathrm{C}$ in a humid incubator with $5 \%$ CO2 concentration. Polyfect transfection reagent (Qiagen) and Calcium phosphate complexes (Invitrogen) were used to transfect HeLa and 293FT cells, respectively. The luciferase reporter (pGL3) whose expression is driven by six E2F responsive elements (6xE2F-Luc) [42] was used for the transcriptional activity of E2F proteins. 293T cells were transfected with 6xE2F-Luc along with increased amounts of HTLV-1 p30 or HTLV-2 p28 expression vectors. After $24 \mathrm{~h}$ of transfection, the cells were starved overnight with media containing 0.5\% FBS and then were serum activated (15\% FBS) for $5 \mathrm{~h}$ followed by luciferase activity assays of the cell extracts as previously reported [42].

\section{Cell cycle and Flow Cytometry analyses}

For cell cycle synchronization and release, $10 \mathrm{~h}$ after transfection (GFP vectors), cells were treated overnight with Hydroxyurea (2 $\mathrm{mM})$ to arrest cells in the G1 phase of the cell cycle. They were next washed and released from block for the time indicated in the figure legends. For the accurate counting of cells going through the cell cycle, in some experiments cells were treated with Nocodazole $(40 \mathrm{ng} / \mathrm{ml})$ after release from Hydroxyurea to block them in G2/M. For the cell cycle distribution analysis, cells were resuspended in media containing the Dye Cycle Violet (Excitation at $405 \mathrm{~nm}$ and Emission at $450 \mathrm{~nm}$ ) (Invitrogen) and incubated for $30 \mathrm{~min}$ at $37^{\circ} \mathrm{C}$ before being analyzed by an LSRII flow cytometer using FACS DIVA 6.1 software.

\section{Immunocytofluorescence staining and microscopy}

GFP or p30-myc expressing viruses have been titered by immuno-fluorescence to reach $100 \%$ of cells transduced. For immunostaining, Hela cells seeded on coverslips were transduced for 48 Hours with the viral particles expressing p30-myc. They were then fixed in 3.7\% Paraformaldehyde (PFA) for $15 \mathrm{~min}$ at RT, washed with PBS for $5 \mathrm{~min}$ followed by permeabilization with $0.5 \%$ Triton X-100 on ice for $5 \mathrm{~min}$. They were next blocked for $1 \mathrm{~h}$ in PBS with $0.5 \%$ gelatin and $0.25 \%$ bovine serum albumin at room temperature. Cells were incubated overnight with anti-myc primary antibody (9E10, Roche), washed 3 times with PBS plus gelatin $0.2 \%$ and then incubated with anti Mouse Alexa-596 conjugated secondary antibody (Invitrogen). They were next washed and mounted by using DABCO mounting medium (2.5\% DABCO from Sigma, 200 mM Tris- $\mathrm{HCl}$ pH8.6 and $90 \%$ glycerol). Fluorescent images were captured by using a Nikon Ti-S epifluorescence microscope equipped with a device camera and the NIS elements software (Nikon). The images were collected by using the objectives $20 \times$ and $100 \times$.

\section{RNA extraction and Real time RT-PCR}

The expression of E2F, cyclinE and p21 was quantified by real time PCR using the Sybr Green method (Applied Biosystems). Briefly, the total mRNA of cells transfected or not transfected with the p30 expression vector was 
extracted by Trizol, DNase-I treated and reverse-transcribed using the High capacity RNA to cDNA kit (Applied Bioscience) as recommended by the manufacturer. Real time PCR (40 cycles) was performed in a total of $25 \mathrm{ul}$ containing RT master mix, water, primers at 0.5 $\mathrm{uM}$ each and cDNA as recommended by the manufacturer using Applied Bioscience Step One plus real time PCR Software. The GAPDH gene was used as an internal amplification control. GAPDH primers: Forward 5'gaaggtgaaggtcggagtc-3' and Reverse 5'-gaagatggtgatgggatttc-3'. Real time primers: cyclinE forward: tcagggtatcagtggtgcga, cyclinE reverse: caaatccaagctgtctctgtg, p21 forward: tgcgttcacaggtgtttctg, p21 reverse: gccattagcgcatcacagt, E2F forward: accctgacctgctgctctt and E2F reverse: tctcggccaggtactgatg. The results are determined by the Relative Standard Curve and comparative $\mathrm{C}_{\mathrm{T}}$ Experiments. The fold $=2^{\text {-DDCT. }}$

\section{Immunoprecipitation, western blots and antibodies}

Cell extracts were prepared using NP-40 lysis buffer ( $1 \%$ NP-40, $50 \mathrm{mM}$ Tris-HcL (pH7.5)), $150 \mathrm{mM} \mathrm{NaCl}$, and a set of proteases (inhibitors). The immunoprecipitation was performed overnight and the proteins were separated by SDS page, transferred to PVDF membrane and western blotted using the standard protocol of WB: Blocking with TBS/Milk 5\%, primary antibody overnight incubation and secondary antibody $2 \mathrm{~h}$ incubation (in TBS Milk 2\%), washed 3 times in TBST $0.05 \%$ and signals were revealed with super signal chemiluminescent substract (Thermo Scientific). Primary antibodies used in this study: Rabbit polyclonal anti phospho(Thr821/ 826)-Rb (Santa Cruz), Goat polyclonal anti Actin sc1615 (Santa Cruz), Rabbit polyclonal anti cyclinE (Santa Cruz C-19 clone), Mouse monoclonal anti-myc tag (9E10) and Mouse monoclonal anti-HA (3F10), Mouse monoclonal anti Flag (Roche), goat polyclonal anti $\mathrm{Rb}$ sc-50-G (Santa Cruz), Rabbit polyclonal anti E2F-1 sc193 (Santa Cruz), Mouse monoclonal anti PCNA (pc10, ZYMED) and Rabbit polyclonal anti p21waf sc-397 (Santa Cruz).

\section{Results}

Using genome-wide microarray analyses, we and others have previously shown that HTLV-I regulatory protein p30 modulates a number of genes involved in the cell cycle. In addition, p30 has been shown to promote the accumulation of cells in the G2-M phase of the cell cycle to facilitate early viral spread and increase $\mathrm{T}$-cell survival following infection [29]. Since our previous data suggested that p30 alters expression of genes involved in G1/S progression [28], we investigated the possible role of p30 in early phases of the cell cycle. To facilitate analyses of p30 expressing cells by FACS, p30 was cloned into a vector containing an internal ribosome entry site
(IRES) fused to the green fluorescent protein (GFP). Cells transfected with GFP-p30 or GFP vector were treated overnight with Hydroxyurea (HU) in order to synchronize cells in the G1 phase of the cell cycle (Figure 1A). Approximately, 75\% of p30-expressing or GFP control cells were successfully blocked in G1, and the percentage of p30-expressing or GFP control cells in $\mathrm{S}$ and $\mathrm{G} 2 / \mathrm{M}$ were similar (Figure 1A). Cells were washed, released from arrest for eight hours before the cells were collected, stained with DyeCycle violet and the GFP expressing cells gated by FACS for cell cycle analyses. Interestingly, while the majority of GFP expressing cells progressed to G2/M phase (green), p30expressing cells were significantly delayed and were still mostly in S phase (red). Since HU did not block $100 \%$ of the cells and to prevent the reentry of cells from $\mathrm{G} 2 / \mathrm{M}$ to $\mathrm{G} 1$, we repeated this experiment in the presence of nocodazole, an inhibitor of the mitotic spindle formation that promotes arrest of Jurkat cells in G2/M [43]. In this experiment the initial time point prior to release is the same as in Figure 1A. The results presented above suggested that p30-expressing cells were delayed in G1/S progression and/or during DNA replication in $\mathrm{S}$ phase. To differentiate between these two possibilities, we analyzed cells four hours after release. Data indicated that $\mathrm{p} 30$-expressing cells were still in G1/S (80\%) while GFP control cells already entered S phase, about $50 \%$ for only $10 \%$ of p30-expressing cells (Figure 1B). These results suggest that p30-expressing cells are mainly delayed at the G1/S border and their entry into $S$ phase. Our results also suggest that p30 delays, but does not block cell cycle progression, since eight hours after release most p30-expressing cells are in $S$ phase $(68 \%)$ (Figure 1B). Again, while most GFP expressing cells are in G2/M (80\%) eight hours after release, only about $20 \%$ of p30-expressing cells are in G2/M (Figure 1B). Collectively, our results demonstrate that p30 prevents normal cell cycle progression, retains cells in G1 and favors a cellular resting state. To confirm our results in human $\mathrm{T}$ cells, the natural target of HTLV-I, we used lentiviral vectors to tansduce p30 or GFP into Jurkat. Twenty four hours after infection, cells were synchronized with $\mathrm{HU}$ and released for cell cycle progression at time $\mathrm{t}=0$ and $\mathrm{t}=8$ hours. The results presented in Figure $1 \mathrm{C}$ further demonstrate that p30 transduced Jurkat cells were significantly delayed in S-phase entry when compared to GFP transduced Jurkat cells.

We next wanted to study the effect of p30 on the expression of endogenous G1/S regulators. Since transfection efficiencies are not sufficient for such studies, we cloned p30 with a carboxy-terminal myc tag into a lentiviral vector. High titer pseudotype virus particles were prepared by transfection of 293FT cells with HR-CMV- 


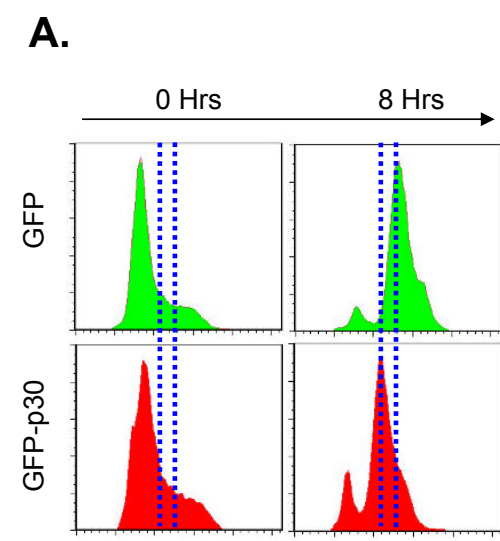

After HU release
B.

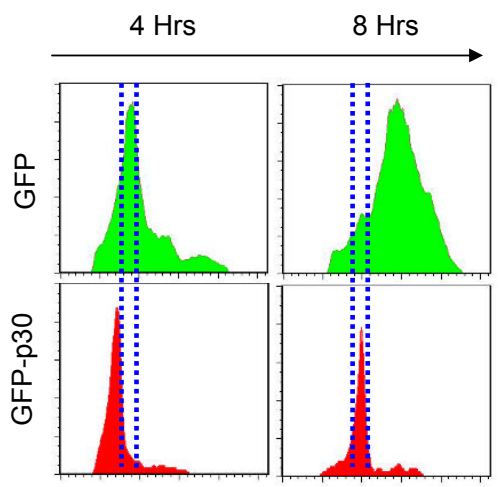

After HU release + Nocodazole
C.

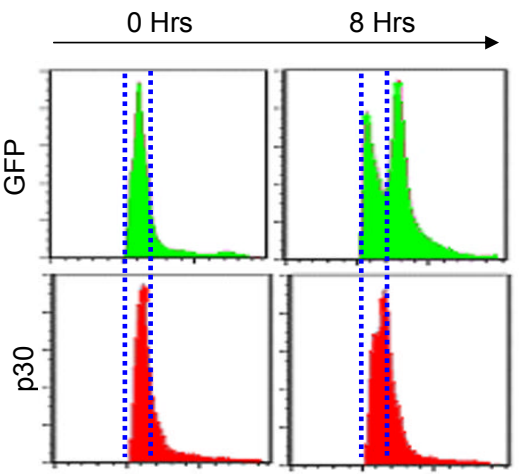

After HU release
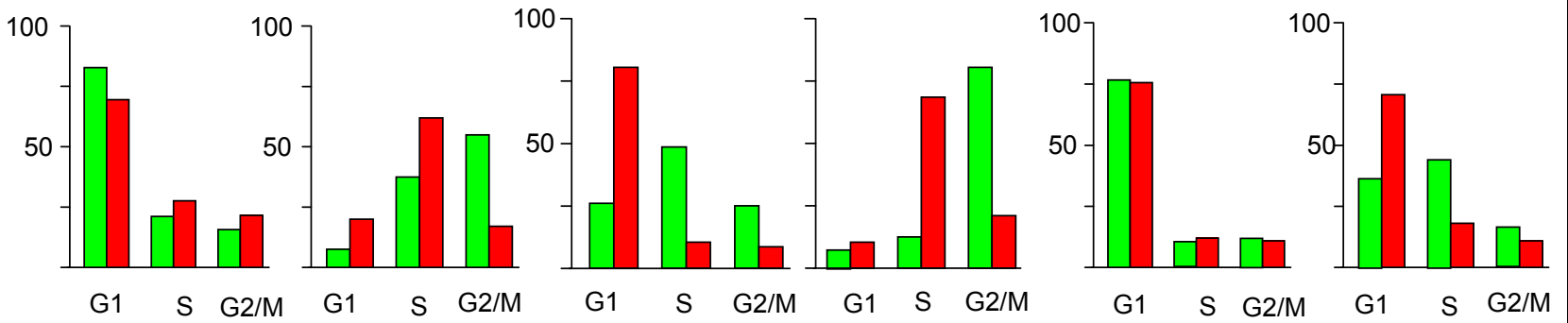

Figure 1 HTLV-1 p30 delays entry of cells into $S$ phase of the cell cycle. Hela cells were transfected with GFP (green) control or GFP-p30 (red) expression vectors synchronized with Hydroxyurea $(2 \mathrm{mM})$ and then released for $0 \mathrm{~h}$ or $8 \mathrm{~h} \mathrm{~A}$ ). B) The same experiment was performed as in A) but after release from "HU" block, cells were immediately treated for $4 \mathrm{~h}$ or $8 \mathrm{~h}$ with Nocodazole $(40 \mathrm{ng} / \mathrm{ml})$ to prevent the reentry of cells from G2/M to G1. The cell cycle was assessed by flow cytometry of GFP positive gated cells. Histograms indicating the percentage of cells in each phase of the cell cycle shown in $\mathbf{A}$ ) and $\mathbf{B}$ ), respectively. C) Jurkat cells infected with lentiviral particles expressing p30 or GFP were synchronized overnight with $\mathrm{HU}(2 \mathrm{mM})$ and then released for $0 \mathrm{~h}$ and $8 \mathrm{~h}$. Cells were stained with propidium iodide (PI) and analyzed by Flow cytometry for the cell cycle distribution using the FACS DIVA 6.1 and FlowJo7.5 Softwares.

p30myc, pDLN and VSV-G. A GFP expressing virus was also prepared in the same conditions, titered by immuno-fluorescence and used as control. Expression of p30 was readily detected by western blot using an antimyc antibody forty-eight hours after infection of HeLa cells (Figure 2A), and, in our experimental conditions, nearly $100 \%$ of cells were transduced, as shown by immuno-fluorescence detection of p30 (Figure 2B). Using the above experimental conditions, we analyzed the expression of proliferating cell nuclear antigen (PCNA), a protein involved in replication of the DNA and required for entry and progression of cells in $S$ phase. The results showed that p30 expression significantly reduced PCNA expression at the protein level (Figure 2C).

We next tested the expression of several regulators of the G1/S transition, E2F, cyclin E and histone H2A, by quantitative real time RT-PCR. Our results showed significant down-regulation of $E 2 F$ and cyclin $E$ mRNA in the presence of p30 (Figure 2D). We did not see any significant change in $\mathrm{H} 2 \mathrm{~A}$ levels (data not shown). These data were further confirmed at the protein level by western blot analyses (Figure 2E). Since E2F is a key transcriptional regulator of genes involved in $\mathrm{S}$ phase entry [44], decreased expression of E2F in part explains the reduced expression of PCNA and cyclin E (Figure $2 \mathrm{C}$ and 2D). Our studies also revealed an increased expression of p21waf CDK-inhibitor at both RNA and protein levels (Figure 2D and 2E). Although many genes, including E2F itself, are transcriptionally regulated by E2F, our results shown in Figure 2F suggested that p30 do not directly affect E2F transcriptional activity. Overall, our results suggest that p30 alters cell cycle progression by targeting multiple checkpoints involved in the G1/S transition, thereby preventing $S$ phase entry.

Whereas cyclin D/cyclin dependent kinase (CDK) 4 and 6 control early G1, progression through $\mathrm{G} 1 / \mathrm{S}$ is controlled by the cyclin E-CDK2 complexes. In the absence of Cyclin E-CDK2 activity, E2F remains bound to $\mathrm{Rb}$ and cannot activate the transcription of genes involved in $\mathrm{S}$ phase entry. Previous studies have shown that Tax directly alters the ratio of $\mathrm{Rb}$-bound and $\mathrm{Rb}$ unbound E2F resulting in activation of E2F-dependent transcription and S-phase entry [45]. Activity of the 


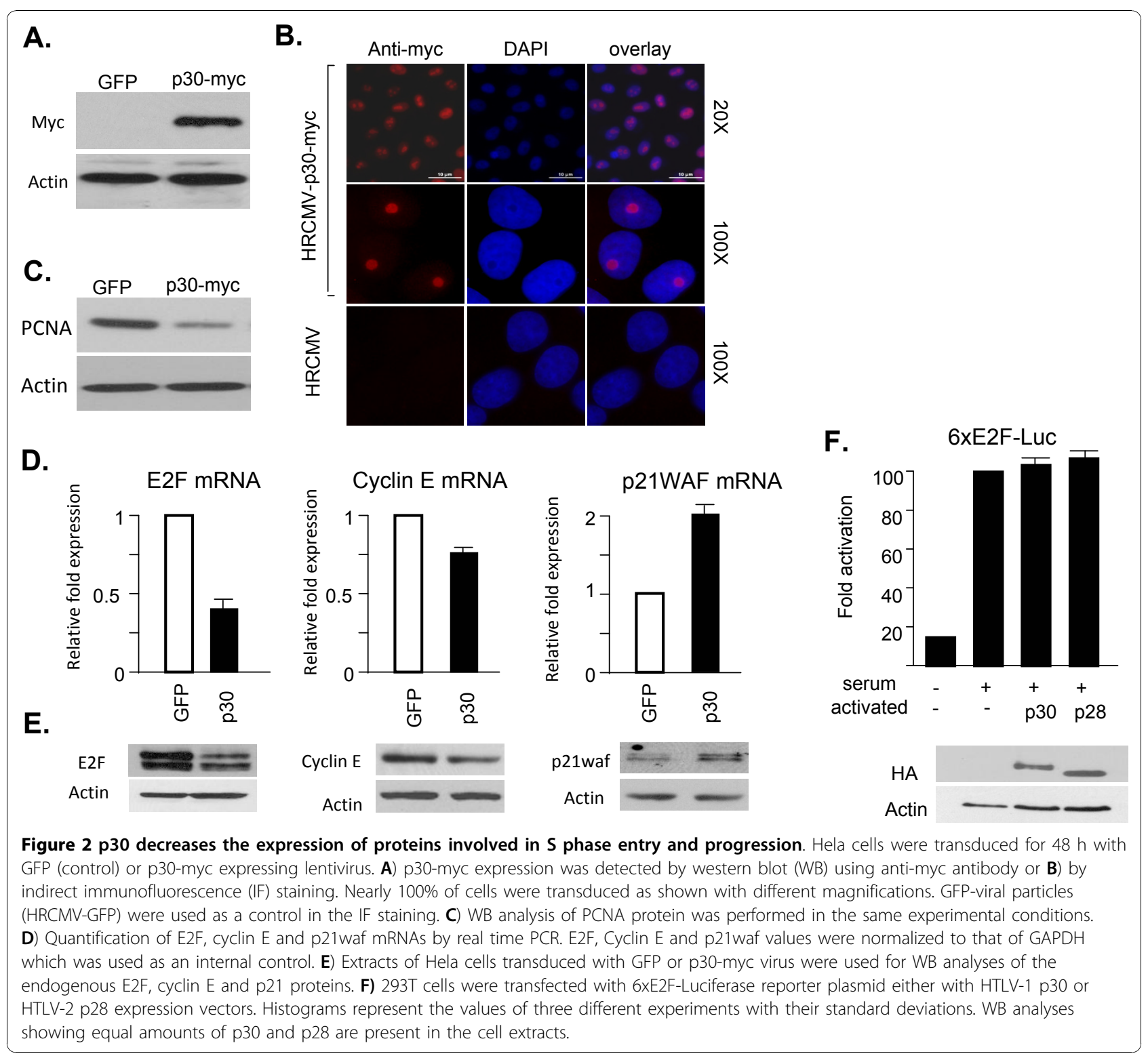

cyclin E-CDK2 complexes occurs through distinct mechanisms, including activation of CDK2 by phosphorylation [46] or alterations in the stoichiometry of cyclin dependent kinase inhibitors (CDKI) p $21^{\text {Waf1 }}$ and p $27^{\text {Kip1 }}$ bound to cyclin E [47]. To identify which of these mechanisms may be associated with p30-mediated inhibition of $\mathrm{G} 1 / \mathrm{S}$ progression, the active form of CDK2 bound to cyclin $\mathrm{E}$ was detected by immuno-precipitation of cyclin E from protein extracts of cells transfected with cyclin E-myc and CDK2-HA in the presence or the absence of p30-Flag. Our results demonstrated that the amounts of active CDK2 bound to cyclin E is severely reduced in the presence of p30 (Figure $3 \mathrm{~A}$ and $3 \mathrm{~B}$ ). Consistent with these findings we also found that in the presence of $\mathrm{p} 30$, decreased amounts of active Cyclin
E-CDK2 complexes correlated with reduced hyperphosphorylation of Rb p107 (Figure 3C). It is well known that in the absence of phosphorylated Rb, E2F cannot be released and cannot activate the transcription of genes required for $S$ phase entry. We next investigated whether p30 may interact with either cyclin E or CDK2. Specific interactions between p30 and cyclin E were readily demonstrated by co-immunoprecipitation and western blot assays after transfection of 293T cells (Figure 3D). Similarly, we found that p30 forms a complex with CDK2 (Figure 3E). Our results suggest that p30 interacts with cyclin E and CDK2 reducing Cyclin E-CDK2 complex formation and phosphorylation of Rb.

While HTLV-I is the etiological agent of ATL and TSP/HAM, infection with HTLV-II is not oncogenic in 


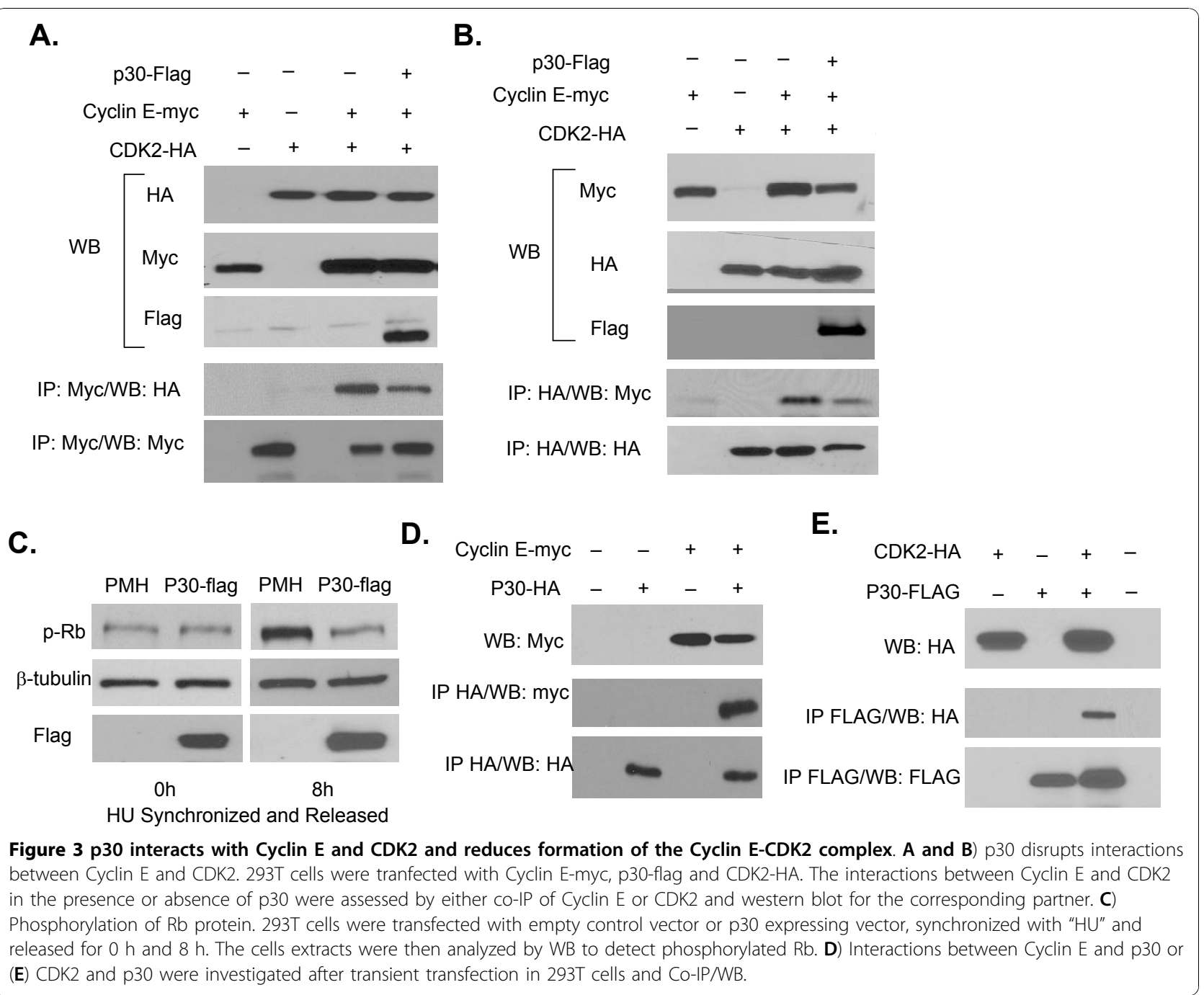

humans. We next investigated the effect of the HTLV-I p30 homologue, HTLV-II p28 [48], on cyclin E and the cell cycle. To compare p30 and p28 biological activities we cloned both viral genes into the same vector $(\mathrm{pMH})$ with the same tag (HA). Following transfection of 293T cells, our results consistently showed that the HTLV-II p 28 protein expressed 25 to 30 fold higher than the p30 protein (Figure 4A). This difference in levels of expression between p30 and p28 was consistently observed and was not related to differences in transfection efficiency (Figure 4B). Using normalized protein amounts, we found that, in contrast to p30, p28 was not able to bind cyclin $\mathrm{E}$ (Figure 4C) following transient expression in 293T cells, unless p28 was overexpressed at extremely high levels (data not shown). Finally, cell cycle analyses revealed that $\mathrm{p} 28$ does not stop the progress of cells in the transition from $\mathrm{G} 1$ to $\mathrm{S}$ phase as does p30 (Figure $4 \mathrm{D}$ and $4 \mathrm{E}$ ), thereby providing the first evidence of a functional difference between these two proteins.

\section{Discussion}

Because HTLV-I is highly immunogenic and presents a low variability, reducing expression of viral proteins is essential to virus maintenance in vivo. In fact, while HTLV-I expression can be detected in TSP/HAM patients, the virus is mainly silent in ATL patients [49] and expansion of infected cells occurs through cell division rather than de novo infection [50]. We have previously discovered that the p30 complex with the tax/ rex mRNA prevents its nuclear export, thereby repressing virus expression [35]. This may be advantageous for the establishment of a latent and persistent infection. We also showed that p30 decreases Toll-like receptor 4 (TLR4) signaling and inhibits the production of proinflammatory cytokines (macrophage chemoattractant protein 1 (MCP-1), tumor necrosis factor alpha (TNF- $\alpha$ ), and interleukin 8 (IL-8)), while increasing the release of the anti-inflammatory cytokine IL-10 [38]. These findings may in part explain the inability of dendritic cells 


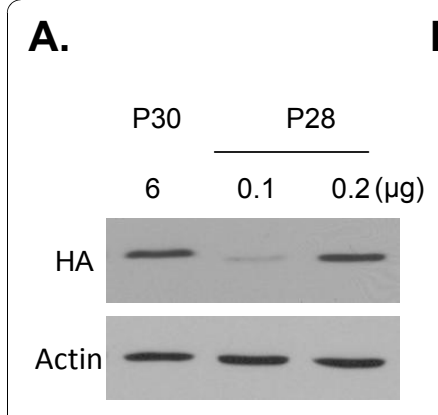

B.

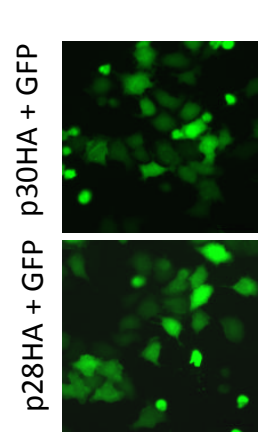

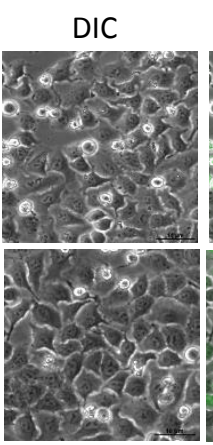

E.
C.

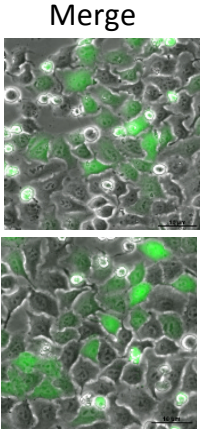

$\begin{array}{rrrrr}\text { Cyclin E-myc } & + & + & + & - \\ \text { P30-HA } & + & - & - & - \\ \text { P28-HA } & - & + & - & -\end{array}$

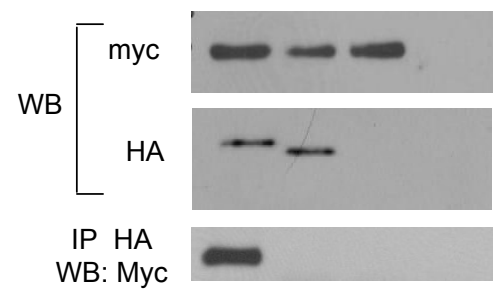

D.

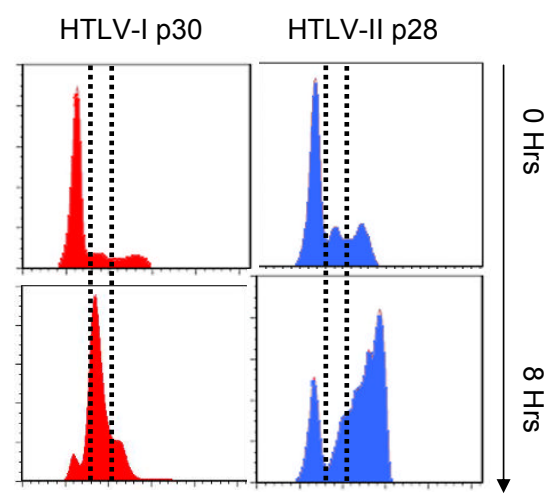

100

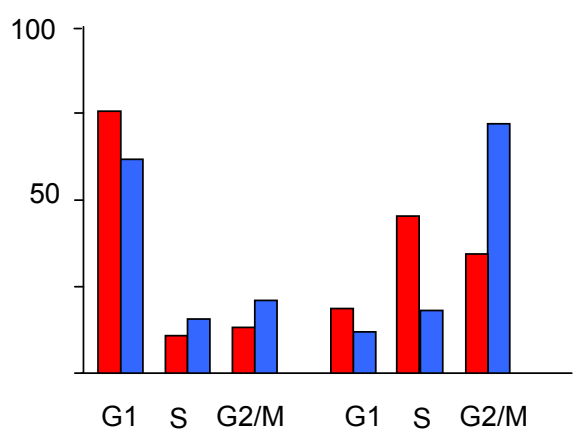

After $\mathrm{HU}$ release

Figure 4 p30 homologue HTLV-2 p28 protein does not interact with Cyclin E and does not affect cell cycle progression. A) 293 T cells were transfected with comparable expression amounts of plasmids expressing p30-HA and p28-HA proteins, WB with HA antibody or actin for loading control. B) Hela cells were transfected with p30HA or p28HA along with GFP expression vector and GFP expression was monitored to demonstrated equivalent transfection efficiencies. C) p28 does not interact with Cyclin E. 293T cells were transfected either with Cylin E-myc and p30-HA or cyclin E-myc and p28-HA. Cell extracts were prepared and the interaction in vivo between Cyclin E and both viral proteins were assessed by co-immunoprecipitation. D) p28 does not affect the cell cycle progression. Hela cells were transfected either with GFP-p30 or GFPp28 expression vectors, synchronized with Hydroxyurea $(2 \mathrm{mM})$ and then released for $0 \mathrm{~h}, 8 \mathrm{~h}$. The cell cycle distribution was assessed by flow cytometry of GFP positive gated cells using the Dye cycle Violet. E) Histograms indicating the percentage of cells in each phase of the cell cycle distribution.

to activate adaptive immunity in ATL patients and the limited proliferation of virus-specific cytotoxic T-lymphocytes (CTL) reported in ATL patients. Previous studies have shown that $\mathrm{p} 30$ can delay the progression of cells during G2/M by enhancing Chk-1 phosphorylation and reducing expression of Polo-like kinase (PLK1) [29].

In the present study, we demonstrate that the HTLV-I accessory protein $\mathrm{p} 30$, but not its HTLV-II homologue p28, delays entry of cells into S phase and cell cycle progression. While proliferation of infected cells is required at times, uncontrolled proliferation of infected cells may lead to their activation and expression of viral genes. Therefore, it seems logical that the virus evolved proteins to balance proliferation as well as mechanisms to prevent infected cells from rapid cell division. Our results demonstrate that $\mathrm{p} 30$ activates multiple $\mathrm{G} 1 / \mathrm{S}$ checkpoints to reduce proliferation. We did not detect any significant change in H2A mRNA levels of expression in p30 expressing cells. We think that this may be due to the fact that p30 targets factors involved in $\mathrm{S}$ phase entry and regulated by E2F. In contrast $\mathrm{H} 2 \mathrm{~A}$ activation is E2F-independent and occurs after cells have entered $\mathrm{S}$ phase. Cyclin-dependent kinase inhibitor (CDKI) p21waf expression was increased in p30 expressing cells. We do not know the mechanism by which p30 increases p21waf expression at the moment and additional studies are needed to investigate whether $\mathrm{p} 30$ affects the expression of p21waf by increasing its promoter expression or mRNA stability. Alternatively p30 may affect other cellular factors involved in p21waf expression such as p53 or Mdm2. We found a significant reduction in E2F and Cyclin E expression at both the transcriptional and protein levels. We do not think that p30 directly affects E2F promoter, since we did not see significant effects of p30 on E2F-mediated transcriptional activation of an E2F reporter construct. Instead, we found that p30 interacts with both Cyclin E and CDK2 preventing the formation of active Cyclin 


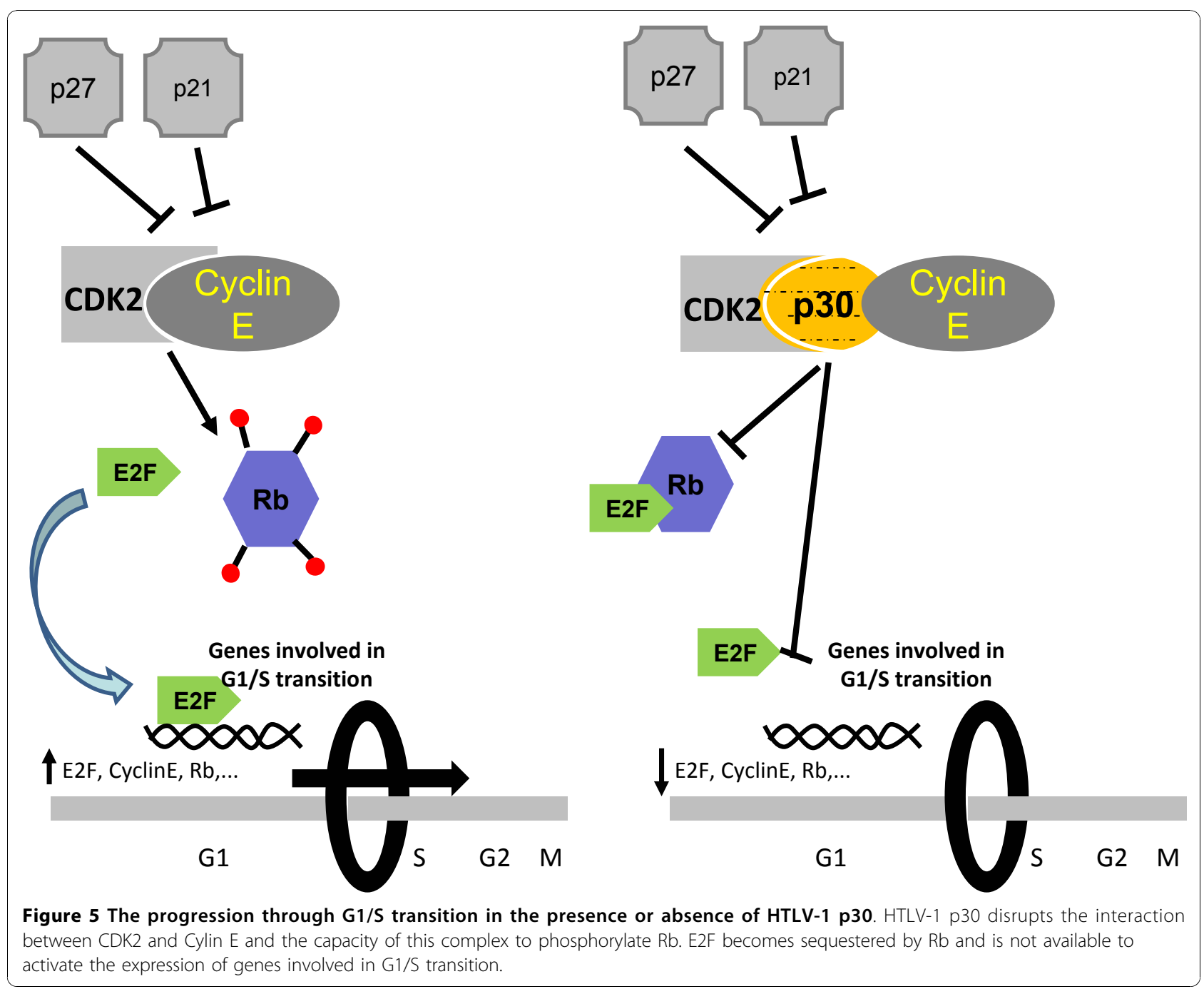

E-CDK2 complexes. Our data may suggest that like p21waf, p30 may form a ternary complex with these proteins further studies are needed to clarify the mechanism. Whether p30 prevents the formation of Cyclin E-CDK2 complexes by sub-cellular compartmentalization to the nucleolus or recruitment of additional cellular factors is currently under investigation. The effects of p30 on the cyclin E-CDK2 complex was associated with a significant decreased phosphorylation of $\mathrm{Rb}$ and delayed entry into $\mathrm{S}$ phase.

In contrast to a previous study [29] using a stable transfected p30 Jurkat cell line, we did not observe a significant delay of p30 expressing cells in progression through G2/M in our assays. While the systems used are quite different, it is possible that selection of p30 expressing cells in that study resulted from elimination of cells with a significant delay in G1/S entry. On the other hand it is possible that the G2/M accumulation previously reported for p30 expressing cells is in fact the result of a delay of these cells in $S$ phase entry. Thus entry of p30 expressing cells into G2/M occurs later while control cells have already completed their cycle and are in G1. In fact, when p30 expressing and control cells were synchronized in G2/M using nocodazole and released we did not see any delayed cell cycle progression from G2/M to G1. However, it is still possible that nocodazole does not block cells early enough in G2 to expose p30 effects. Clearly additional experiments are needed to clarify these issues.

Together our data lead to a model (Figure 5) in which p30 prevents the release of E2F from $\mathrm{Rb}$, thereby preventing E2F-mediated transcription of genes involved in the transition of $\mathrm{G} 1$ to $\mathrm{S}$ as well as its own expression. Interestingly, these effects of p30 would be predicted to antagonize those of Tax, which inactivates or overrides cell cycle checkpoints and stimulates cell proliferation. Differences between Tax and p30 are, however, not completely unexpected given the opposite functions of 
these two proteins during the virus life cycle. Interestingly, our data demonstrate that the HTLV-II p28 protein does not interact with cyclin $\mathrm{E}$ and does not significantly impair cell cycle progression. This is the first report of a physiological difference between p30 and p28. Because HTLV-I, but not HTLV-II, is associated with leukemias, any difference between these viruses may offer some clues about the determinant of viral pathogenesis of HTLV-I.

In addition to p30, other HTLV-I-encoded small proteins play a critical role in evasion of infected cells to immune defenses and survival of tumor cells. p12 has been shown to down regulate MHC class I from the cell surface and to increase the release of calcium from the endoplasmic reticulum to activate NFAT-mediated transcription [30,31,51-54]. Finally, proteolytic processing of p12 generates a shorter $8-\mathrm{kDa}$ protein that migrates to the cell surface, interacts with the immunologic synapse following engagement of the T-cell receptor (TCR), and down-regulates TCR signaling [55]. p13, a mitochondrial protein, induces a delay in all phases of the cell cycle and appears to be mediated by up-regulation of a heatsensitive cellular cytostatic factor [27]. These studies suggest that HTLV-I accessory proteins may play critical roles in slowing the replication of HTLV-I infected cells in vivo to prevent their elimination by the host's immune cells. A better understanding of how this is achieved may offer new ways to interfere with viral latency, expose infected cells to the immune system and help their eradication.

\section{List of abbreviations}

E2F: HTLV-1; PCNA: Rb.

\section{Acknowledgements}

The authors thank Dr. P. Green (Ohio State University, Ohio) for the HTLV-II p28 expression vector, Dr. James M. Roberts (Fred Hutchinson Cancer Research (enter, Seattle) for the CDK2 and Cyclin E expression vectors and Dr. Ole Gjoerup for the E2F-Luciferase reporter construct. Authors also thank Elizabeth Jenkins for editorial assistance.

Financial Support: This work was supported by the National Institute of Allergy and Infectious Diseases grant Al058944 to C.N. The content is solely the responsibility of the authors and does not necessarily represent the official views of the National Institute of Allergy and Infectious Diseases or the National Institutes of Health.

\section{Authors' contributions}

HB performed experiments for figures 1, 2, 3, 4 and 5 and wrote the paper JP performed experiments for figures 2 and 3. BXT performed experiments for figures 3 and 4 . CN designed the study, interpreted the data and wrote the paper. All authors read and approved the final manuscript.

\section{Competing interests}

The authors declare that they have no competing interests.

Received: 15 June 2010 Accepted: 23 November 2010 Published: 23 November 2010
References

1. Sherr CJ, Roberts JM: Living with or without cyclins and cyclin-dependent kinases. Genes Dev 2004, 18:2699-2711.

2. van den Heuvel S, Dyson NJ: Conserved functions of the pRB and E2F families. Nat Rev Mol Cell Biol 2008, 9:713-724.

3. Zhang HS, Gavin M, Dahiya A, Postigo AA, Ma D, Luo RX, Harbour JW, Dean DC: Exit from $\mathrm{G} 1$ and $S$ phase of the cell cycle is regulated by repressor complexes containing HDAC-Rb-hSWI/SNF and Rb-hSWI/SNF. Cell 2000, 101:79-89.

4. Lees E, Faha B, Dulic V, Reed SI, Harlow E: Cyclin E/cdk2 and cyclin A/cdk2 kinases associate with $\mathrm{p} 107$ and E2F in a temporally distinct manner. Genes Dev 1992, 6:1874-1885.

5. Dulic V, Lees E, Reed SI: Association of human cyclin E with a periodic G1-S phase protein kinase. Science 1992, 257:1958-1961.

6. Hinds PW, Mittnacht S, Dulic V, Arnold A, Reed SI, Weinberg RA: Regulation of retinoblastoma protein functions by ectopic expression of human cyclins. Cell 1992, 70:993-1006.

7. Sheaff RJ, Groudine M, Gordon M, Roberts JM, Clurman BE: Cyclin E-CDK2 is a regulator of p27Kip1. Genes Dev 1997, 11:1464-1478.

8. Vlach J, Hennecke S, Amati B: Phosphorylation-dependent degradation of the cyclin-dependent kinase inhibitor p27. EMBO J 1997, 16:5334-5344.

9. Harbour JW, Dean DC: The Rb/E2F pathway: expanding roles and emerging paradigms. Genes Dev 2000, 14:2393-2409.

10. Yu Q, Sicinski P: Mammalian cell cycles without cyclin E-CDK2. Cell Cycle 2004, 3:292-295.

11. Le Cam L, Polanowska J, Fabbrizio E, Olivier M, Philips A, Ng EE, Classon M, Geng Y, Sardet C: Timing of cyclin E gene expression depends on the regulated association of a bipartite repressor element with a novel E2F complex. EMBO J 1999, 18:1878-1890.

12. Poiesz BJ, Ruscetti FW, Gazdar AF, Bunn PA, Minna JD, Gallo RC: Detection and isolation of type $C$ retrovirus particles from fresh and cultured lymphocytes of a patient with cutaneous T-cell lymphoma. Proc Natl Acad Sci USA 1980, 77:7415-7419.

13. Hinuma $Y$, Nagata $K$, Hanaoka M, Nakai M, Matsumoto T, Kinoshita Kl, Shirakawa S, Miyoshi I: Adult T-cell leukemia: antigen in an ATL cell line and detection of antibodies to the antigen in human sera. Proc Natl Acad Sci USA 1981, 78(10):6476-80.

14. Gessain A, Barin F, Vernant JC, Gout O, Maurs L, Calender A, de The G: Antibodies to human T-lymphotropic virus type-I in patients with tropical spastic paraparesis. Lancet 1985, 2:407-410.

15. Osame M, Matsumoto M, Usuku K, Izumo S, ljichi N, Amitani H, Tara M, Igata $A$ : Chronic progressive myelopathy associated with elevated antibodies to human T-lymphotropic virus type I and adult T-cell leukemialike cells. Ann Neurol 1987, 21:117-122.

16. Franchini G, Nicot $C$, Johnson JM: Seizing of $T$ cells by human T-cell leukemia/lymphoma virus type 1. Adv Cancer Res 2003, 89:69-132.

17. Marriott SJ, Semmes OJ: Impact of HTLV-I Tax on cell cycle progression and the cellular DNA damage repair response. Oncogene 2005, 24:5986-5995.

18. Neuveut $C$, Jeang KT: Cell cycle dysregulation by HTLV-I: role of the tax oncoprotein. Front Biosci 2002, 7:d157-d163.

19. Lemoine FJ, Marriott SJ: Accelerated $G(1)$ phase progression induced by the human T cell leukemia virus type I (HTLV-I) Tax oncoprotein. J Biol Chem 2001, 276:31851-31857.

20. de la Fuente C, Deng L, Santiago F, Arce L, Wang L, Kashanchi F: Gene expression array of HTLV type 1-infected T cells: Up-regulation of transcription factors and cell cycle genes. AIDS Res Hum Retroviruses 2000, 16:1695-1700

21. Schmitt I, Rosin O, Rohwer P, Gossen M, Grassmann R: Stimulation of cyclin-dependent kinase activity and G1- to S-phase transition in human lymphocytes by the human T-cell leukemia/lymphotropic virus type 1 Tax protein. J Virol 1998, 72:633-640.

22. Cereseto A, Diella F, Mulloy JC, Cara A, Michieli P, Grassmann R, Franchini G, Klotman ME: p53 functional impairment and high p21waf1/cip1 expression in human T-cell lymphotropic/leukemia virus type Itransformed T cells. Blood 1996, 88:1551-1560.

23. Suzuki T, Kitao S, Matsushime H, Yoshida M: HTLV-1 Tax protein interacts with cyclin-dependent kinase inhibitor p16INK4A and counteracts its inhibitory activity towards CDK4. EMBO J 1996, 15:1607-1614. 
24. Liu M, Yang L, Zhang L, Liu B, Merling R, Xia Z, Giam CZ: Human T-cell leukemia virus type 1 infection leads to arrest in the G1 phase of the cell cycle. J Virol 2008, 82:8442-8455.

25. Kuo YL, Giam CZ: Activation of the anaphase promoting complex by HTLV-1 tax leads to senescence. EMBO J 2006, 25:1741-1752.

26. Bellon M, Baydoun HH, Yao Y, Nicot C: HTLV-I Tax-dependent and -independent events associated with immortalization of human primary T lymphocytes. Blood 2010, 115:2441-2448.

27. Silic-Benussi M, Cavallari I, Zorzan T, Rossi E, Hiraragi H, Rosato A, Horie K, Saggioro D, Lairmore MD, Willems L, Chieco-Bianchi L, D’Agostino DM, Ciminale V: Suppression of tumor growth and cell proliferation by p13ll, a mitochondrial protein of human T cell leukemia virus type 1. Proc Natl Acad Sci USA 2004, 101:6629-6634.

28. Taylor JM, Ghorbel S, Nicot C: Genome wide analysis of human genes transcriptionally and post-transcriptionally regulated by the HTLV-I protein p30. BMC Genomics 2009, 10:311.

29. Datta A, Silverman L, Phipps AJ, Hiraragi H, Ratner L, Lairmore MD: Human T-lymphotropic virus type- 1 p30 alters cell cycle $\mathrm{G} 2$ regulation of $\mathrm{T}$ lymphocytes to enhance cell survival. Retrovirology 2007, 4:49.

30. Taylor JM, Brown M, Nejmeddine M, Kim KJ, Ratner L, Lairmore M, Nicot C: Novel role for interleukin-2 receptor-Jak signaling in retrovirus transmission. J Virol 2009, 83:11467-11476.

31. Fukumoto R, Dundr M, Nicot C, Adams A, Valeri WW, Samelson LE, Franchini G: Inhibition of T-cell receptor signal transduction and viral expression by the linker for activation of T cells-interacting p12(l) protein of human T-cell leukemia/lymphoma virus type 1. J Virol 2007, 81:9088-9099.

32. Ding W, Kim SJ, Nair AM, Michael B, Boris-Lawrie K, Tripp A, Feuer G, Lairmore MD: Human T-cell lymphotropic virus type 1 p12l enhances interleukin-2 production during T-cell activation. J Virol 2003, 77:11027-11039.

33. Nicot C, Mulloy JC, Ferrari MG, Johnson JM, Fu K, Fukumoto R, Trovato R, Fullen J, Leonard WJ, Franchini G: HTLV-1 p12(I) protein enhances STAT5 activation and decreases the interleukin-2 requirement for proliferation of primary human peripheral blood mononuclear cells. Blood 2001, 98:823-829.

34. Arnold J, Zimmerman B, Li M, Lairmore MD, Green PL: Human T-cell leukemia virus type- 1 antisense-encoded gene, $\mathrm{Hbz}$, promotes T-lymphocyte proliferation. Blood 2008, 112:3788-3797.

35. Nicot C, Dundr M, Johnson JM, Fullen JR, Alonzo N, Fukumoto $R$, Princler GL, Derse D, Misteli T, Franchini G: HTLV-1-encoded p30ll is a post-transcriptional negative regulator of viral replication. Nat Med 2004, 10:197-201.

36. Sinha-Datta U, Datta A, Ghorbel S, Dodon MD, Nicot C: Human T-cell lymphotrophic virus type I rex and p30 interactions govern the switch between virus latency and replication. J Biol Chem 2007, 282:14608-14615.

37. Baydoun HH, Bellon M, Nicot C: HTLV-1 Yin and Yang: Rex and p30 master regulators of viral mRNA trafficking. AIDS Rev 2008, 10:195-204

38. Datta A, Sinha-Datta U, Dhillon NK, Buch S, Nicot C: The HTLV-I p30 interferes with TLR4 signaling and modulates the release of pro- and anti-inflammatory cytokines from human macrophages. J Biol Chem 2006, 281:23414-23424.

39. Zhang W, Nisbet JW, Albrecht B, Ding W, Kashanchi F, Bartoe JT, Lairmore MD: Human T-lymphotropic virus type 1 p30(II) regulates gene transcription by binding CREB binding protein/p300. J Virol 2001, 75:9885-9895.

40. Zhang W, Nisbet JW, Bartoe JT, Ding W, Lairmore MD: Human Tlymphotropic virus type 1 p30(II) functions as a transcription factor and differentially modulates CREB-responsive promoters. J Virol 2000, 74:11270-11277.

41. Welcker M, Singer J, Loeb KR, Grim J, Bloecher A, Gurien-West M, Clurman BE, Roberts JM: Multisite phosphorylation by Cdk2 and GSK3 controls cyclin E degradation. Mol Cell 2003, 2:381-92

42. Gjoerup O, Lukas J, Bartek J, Willumsen BM: Rac and Cdc42 Are Potent Stimulators of E2F-dependent Transcription Capable of Promoting Retinoblastoma Susceptibility Gene Product Hyperphosphorylation. J Biol Chem 1998, 273:18812-18818.

43. Bellon M, Baydoun HH, Yao Y, Nicot C: HTLV-I Tax-dependent and -independent events associated with immortalization of human primary T lymphocytes. Blood 2010, 115(12):2441-2448.
44. Blais A, Dynlacht BD: E2F-associated chromatin modifiers and cell cycle control. Curr Opin Cell Biol 2007, 19:658-662.

45. Lemasson I, Thebault S, Sardet C, Devaux C, Mesnard JM: Activation of E2Fmediated transcription by human T-cell leukemia virus type I Tax protein in a p16(INK4A)-negative T-cell line. J Biol Chem 1998, 273:23598-23604.

46. Gu Y, Rosenblatt J, Morgan DO: Cell cycle regulation of CDK2 activity by phosphorylation of Thr160 and Tyr15. EMBO J 1992, 11:3995-4005.

47. Cereseto A, Washington Parks R, Rivadeneira E, Franchini G: Limiting amounts of p27Kip1 correlates with constitutive activation of cyclin ECDK2 complex in HTLV-I-transformed T-cells. Oncogene 1999, 18(15):2441-2450.

48. Yamamoto B, Li M, Kesic M, Younis I, Lairmore MD, Green PL: Human T-cell leukemia virus type 2 post-transcriptional control protein p28 is required for viral infectivity and persistence in vivo. Retrovirology 2008, 5:38.

49. Furukawa Y, Osame M, Kubota R, Tara M, Yoshida M: Human T-cell leukemia virus type-1 (HTLV-1) Tax is expressed at the same level in infected cells of HTLV-1-associated myelopathy or tropical spastic paraparesis patients as in asymptomatic carriers but at a lower level in adult T-cell leukemia cells. Blood 1995, 85:1865-1870.

50. Mortreux F, Leclercq I, Gabet AS, Leroy A, Westhof E, Gessain A, WainHobson S, Wattel E: Somatic mutation in human T-cell leukemia virus type 1 provirus and flanking cellular sequences during clonal expansion in vivo. J Natl Cancer Inst 2001, 93(5):367-77.

51. Kim SJ, Ding W, Albrecht B, Green PL, Lairmore MD: A conserved calcineurin-binding motif in human T lymphotropic virus type $1 \mathrm{p} 12 \mathrm{l}$ functions to modulate nuclear factor of activated T cell activation. J Biol Chem 2003, 278:15550-15557.

52. Albrecht B, Lairmore MD: Critical role of human T-lymphotropic virus type 1 accessory proteins in viral replication and pathogenesis. Microbiol Mol Biol Rev 2002, 66:396-406.

53. Johnson JM, Nicot C, Fullen J, Ciminale V, Casareto L, Mulloy JC, Jacobson S, Franchini G: Free major histocompatibility complex class I heavy chain is preferentially targeted for degradation by human T-cell leukemia/lymphotropic virus type 1 p12(I) protein. J Virol 2001, 75:6086-6094.

54. Albrecht B, Collins ND, Burniston MT, Nisbet JW, Ratner L, Green PL, Lairmore MD: Human T-lymphotropic virus type 1 open reading frame I $\mathrm{p} 12(\mathrm{I})$ is required for efficient viral infectivity in primary lymphocytes. J Virol 2000, 74:9828-9835.

55. Fukumoto R, Andresen V, Bialuk I, Cecchinato V, Walser JC, Valeri WW, Nauroth JM, Gessain A, Nicot C, Franchini G: In vivo genetic mutations define predominant functions of the human T-cell leukemia/lymphoma virus p12I protein. Blood 2009, 113:3726-3734.

doi:10.1186/1476-4598-9-302

Cite this article as: Baydoun et al:: HTLV-I p30 inhibits multiple $S$ phase entry checkpoints, decreases cyclin E-CDK2 interactions and delays cell cycle progression. Molecular Cancer 2010 9:302.

\section{Submit your next manuscript to BioMed Central and take full advantage of:}

- Convenient online submission

- Thorough peer review

- No space constraints or color figure charges

- Immediate publication on acceptance

- Inclusion in PubMed, CAS, Scopus and Google Scholar

- Research which is freely available for redistribution

Submit your manuscript at www.biomedcentral.com/submit
C Biomed Central 